\title{
Comparative study of follow-up in high-risk infants and normal infants for development and neurological status in a tertiary hospital in Navimumbai, India
}

\author{
*Vijay Baburao Sonawane ${ }^{1}$, Sheenu Veeranna Gupta ${ }^{2}$, Veeranna Kotrashetti ${ }^{3}$, Prashant Abusaria ${ }^{4}$
}

Sri Lanka Journal of Child Health, 2021; 50(4): 583-588

DOI: http://doi.org/10.4038/sljch.v50i4.9842

\begin{abstract}
Background: 'High-risk-infants' denote infants who should be closely observed by experienced doctors and nurses. There are numerous studies evaluating the outcome of asphyxiated babies, preterm babies and extremely low birth weight infants. However, there are very few studies that evaluate the outcome in terms of a development and neurological status of a composite high-risk cohort.
\end{abstract}

Objectives: 1) Study the development and neurological status of high-risk infants and normal infants comparing the patterns. 2) Early detection of development failures and development delays. 3) Early initiation of interventional therapy.

Method: A hospital-based prospective case control study was carried out at the Department of Paediatrics, Dr. D.Y. Patil Medical College, Hospital and Research Centre, Nerul, NaviMumbai, India. Consecutive type of non-probability sampling was used for selection of cases. Thirty high-risk neonates were included in the study as Cases. Thirty Controls were also taken, who were without any high risk factor. At follow up, developmental and neurological status assessments were done. Neonatal reflexes and goniometry were done for measurement of various angles at the joints. Trivandrum developmental scoring was used to assess development while Amiel Teison method was employed to assess the neurological status.

\section{${ }^{1}$ Associate Professor, Department of Paediatrics, $D$. Y. Patil University, School of Medicine, Nerul, Maharashtra. India, ${ }^{2}$ Consulting Paediatrician, NaviMumbai Tertiary Hospital, Maharashtra. India, ${ }^{3}$ Professor and Head of Unit, ${ }^{4}$ Resident $(P G)$, Department of Paediatrics, D. Y. Patil University, School of Medicine, Nerul, Maharashtra, India, *Correspondence: vijay_ltm@yahoo.co.in}

https://orcid.org/0000-0003-3517-8645

(Received on 30 August 2020: Accepted after revision on 16 October 2020)

The authors declare that there are no conflicts of interest

Personal funding was used for the project.

Open Access Article published under the Creative

Commons Attribution CC-BY (c) (i) License
Ophthalmological assessment was done for neonatal screening of retinopathy of prematurity (ROP) and Brainstem Evoked Response Audiometry (BERA) test was done for hearing assessment. Data were analysed using statistical software SPSS version 21.

Results: Overall, 33 (55\%) newborns were females and $27(45 \%)$ were males with no significant differences between study and control groups $(\mathrm{p}=1.0)$. All controls were term babies while in study group $16(53.3 \%)$ were pre-term and $4(13.3 \%)$ were post-term. Of the 30 cases with risk factors, 25 were low birth weight. Mean gestational age and birth weight were significantly less in Cases as compared to Controls $(\mathrm{p}<0.05)$. On follow up, $2(6.7 \%)$ cases had a head circumference below the $3^{\text {rd }}$ percentile and $11(36.7 \%)$ cases had deranged reflexes. Only 1 case had abnormal ophthalmic examination findings and none had auditory abnormalities. On neurological assessment by Amiel Tison scale, $66.7 \%$ cases were observed to have deranged neurological development. At 6 months of age, $36.7 \%$ of the cases with risk factors had developmental delay.

Conclusions: In this study the incidence of developmental and neuro-developmental delay in high-risk neonates was significantly high with low birth weight and prematurity being the main contributors.

(Key words: High-risk infants, Trivandrum developmental scoring system, Neonatal reflexes, Development and neurological status, Amiel Tison scale).

\section{Introduction}

The term 'high-risk infants' denotes infants who should be closely monitored by experienced doctors and nurses. Around 9\% births need special care ${ }^{1}$. Although there is a marked improvement in neonatal survival, chronic morbidities and adverse outcomes in survivors are still high ${ }^{2-4}$. There are numerous studies evaluating the outcome of asphyxiated babies, preterm babies, and extremely low birth weight infants. However, there are very few studies that evaluate the neurodevelopmental outcome of a composite high-risk cohort ${ }^{5-10}$. The present study aimed at comparing the patterns of development and neurological status of the normal infants and high- 
risk infants by using different parameters like Trivandrum development scale, anthropometry, neurological examination using neonatal reflexes and Amiel Tison method and ophthalmological and audiometric examination. These parameters will help us to understand the possible deviation in the normal course of development of high-risk infants and early intervention if any signs of developmental disorder are present.

\section{Objectives}

1. To study the development and neurological status of high-risk infants and normal infants comparing the patterns

2. Early detection of development failures and development delays in high-risk infants

3. Early initiation of interventional therapy.

\section{Method}

Study area: Department of Paediatrics, Dr. D.Y. Patil Medical College, Hospital and Research Centre.

Study design: A prospective, observational, case control study.

Sample size: Consecutive type of non-probability sampling was used for selection of cases. Thirty high-risk neonates were included in study as Cases. Thirty Controls were also taken, who were without any risk factors. Matching was done by taking hospital controls of same age group and same sex.

Study duration: Period of 6 months

Inclusion criteria:

1. Early preterm ( $<34$ weeks) and post term (>40 weeks)

2. Perinatal asphyxia and hypoxic ischaemic encephalopathy (HIE)

3. Infection - antenatal, natal and post-natal

4. Seizures

5. Respiratory distress, meconium aspiration syndrome and apnoea

6. Cardiopulmonary instability (including neonates on vasopressors)

7. Metabolic disturbances - hypoglycaemia, electrolytic imbalance and hypocalcaemia

8. Hyperbilirubinaemia $>20 \mathrm{mg} / \mathrm{dl}$

\section{Exclusion criteria:}

1. Preterm $>34$ weeks and weight $>1800 \mathrm{~g}$

2. Babies who did not come for follow up more than once in the 6 months.

Informed consent was taken from parents or guardians of the babies satisfying the inclusion criteria. Prenatal and postnatal risk factors were assessed among study participants. Gestational age was obtained through obstetrical estimates based on first trimester ultrasonography or by date of last menstrual period.
Trivandrum developmental scoring was used for assessing development while neonatal reflexes and Amiel Tieson method was employed for neurological status assessment.

Trivandrum Developmental Screening Chart (TDSC): A plastic ruler or a pencil was kept vertically at the corrected age of the child being tested. If the child failed to pass any item that lies to the left side of the age marker, the child was considered to have developmental delay. As in this study, the follow up was kept till the age of six months, 6 test items were used namely social smile, eyes following pen / pencil, holding head steady, rolling from back to stomach, turning head to sound of bell/rattle and transferring object from hand to hand.

Evaluation of passive tone by Amiel-Tison method: Evaluation of passive tone was determined by extensibility and amplitude of flapping different segments of the extremities. Findings were disregarded if patient was drowsy or agitated. The following tests were used-

1. Adductor angle: With the infant lying supine and, in the midline, the legs were extended and pulled as far apart as possible and the angle formed between the legs was taken as adductor angle with the help of a goniometer. Any asymmetry between the right and the left was noted. Index fingers were aligned over thighs to measure the angle. If the child was hypertonic, the angle was found to be narrow and resistance was encountered during the test. Table 1 shows the normal range of adductor angle in infancy

Table 1

Normal range of adductor angle in infancy

\begin{tabular}{|l|c|}
\hline \multicolumn{1}{|c|}{ Age (months) } & Angle (degree) \\
\hline 0 to 3 & 40 to 80 \\
\hline 4 to 6 & 70 to 110 \\
\hline 7 to 9 & 110 to 140 \\
\hline 10 to 12 & 140160 \\
\hline
\end{tabular}

2. Popliteal angle: In the supine position, the hips were completely flexed on to the abdomen by holding at the knees, the legs were then extended by gentle pressure with the examiner's hand placed behind the legs and popliteal angle was measured by a goniometer. Significant asymmetry is indicated by a difference of 10 to 20 degrees. Table 2 shows the normal range of popliteal angle in infancy. 
Table 2

Normal range of popliteal angle in infancy

\begin{tabular}{|l|c|}
\hline \multicolumn{1}{|c|}{ Age (months) } & Angle (degree) \\
\hline 0 to 3 & 80 to 100 \\
\hline 4 to 6 & 90 t0 120 \\
\hline 7 to 9 & 110 to 160 \\
\hline 10 to 12 & 150170 \\
\hline
\end{tabular}

3. Dorsiflexion angle of the foot: The legs of the patient were held straight and flexion of the foot towards the tibia was done by applying pressure with the thumb to the sole. The dorsiflexion angle of the foot is the angle formed by the foot and anterior aspect of the foot. This angle was tested on each side separately. First a slow moderate pressure is applied to measure the smallest dorsiflexion angle called the slow angle. This is followed by a rapid, quick and sudden flexion to determine the rapid angle. Normally both angles are equal. A difference between the rapid and slow angles of more than 10 degrees indicate an abnormally exaggerated stretch reflex. Table 3 shows the normal range of dorsiflexion angle of the foot in infancy.

Table 3

Normal range of dorsiflexion angle of foot in infancy

\begin{tabular}{|l|c|}
\hline \multicolumn{1}{|c|}{ Age (months) } & Angle (degree) \\
\hline 0 to 3 & 60 to 70 \\
\hline 4 to 6 & 60 to 70 \\
\hline 7 to 9 & 60 to 70 \\
\hline 10 to 12 & 60 o 70 \\
\hline
\end{tabular}

4. Scarf sign: In the supine position, with the upper limb flexed at the elbow, was pulled as far as possible across the chest by holding the hand and the wrist. Scarf sign may be limited if the baby is obese or extremely irritable. Table 4 shows the normal range of scarf sign.
Table 4: Normal range of scarf sign

\begin{tabular}{|l|l|}
\hline \multicolumn{1}{|c|}{$\begin{array}{c}\text { Age } \\
\text { (months) }\end{array}$} & \multicolumn{1}{c|}{ Scarf sign } \\
\hline 0 to 3 & Elbow does not cross the midline \\
\hline 4 to 6 & Elbow crosses the midline \\
\hline 7 to 9 & $\begin{array}{l}\text { Elbow goes beyond anterior } \\
\text { axillary line }\end{array}$ \\
\hline
\end{tabular}

Ophthalmological assessment was done for neonatal screening for ROP \& BERA test was done for hearing assessment.

Ethical issues: Ethical approved was obtained from the Institutional Ethics Committee, D.Y. Patil Medical College Hospital and Research Centre, Nerul, NaviMumbai, India (No. PDDYPMC/ Ethics/PG Dissert/2016 dated 25/11/2016). Written informed consent was taken from parents or guardians of the babies in the study.

Statistical analysis: Quantitative data was represented by mean $\pm \mathrm{SD}$. Categorical and nominal data were expressed in percentages. The t-test was used for analysing quantitative data, or else nonparametric data were analysed by Mann Whitney test and categorical data by using Chi-square test. $p$ $<0.05$ was considered significant. Analysis was done using SPSS version 21. Subsequently, measurements were repeated at discharge and then at $6,10,14$ weeks and 6 months of age. At follow up, developmental assessment was done.

\section{Results}

The distribution of cases according to gender is shown in Table 5.

Overall 33 (55\%) newborns were females and 27 $(45 \%)$ were males with no difference between study groups $(\mathrm{p}=1.0)$.

The distribution of cases according to gestational age is shown in Table 6.

All the controls were term babies while in controls, $16(53.3 \%)$ cases were pre-term and $4(13.3 \%)$ were post-term.

The distribution of cases according to birth weight is shown in Table 7.

Table 5: Distribution of Cases according to gender

\begin{tabular}{|l|c|c|c|}
\hline \multirow{2}{*}{ Gender } & \multicolumn{2}{|c|}{ Group } & \multirow{2}{*}{$\begin{array}{c}\text { Total } \\
\text { n (\%) }\end{array}$} \\
\cline { 2 - 4 } & $\begin{array}{c}\text { Cases } \\
\text { n (\%) }\end{array}$ & $\begin{array}{c}\text { Controls } \\
\mathbf{n}(\mathbf{\%})\end{array}$ & \\
\hline Female & $17(56.7)$ & $16(53.3)$ & $33(55.0)$ \\
\hline Male & $13(43.3)$ & $14(46.7)$ & $27(45.0)$ \\
\hline Total & $30(100.0)$ & $30(100.0)$ & $60(100.0)$ \\
\hline & \multicolumn{2}{|c|}{$\mathbf{p = 1 . 0}$} & \\
\hline
\end{tabular}


Table 6: Distribution of Cases according to gestational age

\begin{tabular}{|l|c|c|c|}
\hline \multirow{2}{*}{ Gestational age } & \multicolumn{2}{|c|}{ Group } & \multirow{2}{*}{$\begin{array}{c}\text { Total } \\
\text { n (\%) }\end{array}$} \\
\cline { 2 - 4 } & $\begin{array}{c}\text { Cases } \\
\text { n (\%) }\end{array}$ & $\begin{array}{c}\text { Controls } \\
\text { n (\%) }\end{array}$ & \\
\hline Pre-term & $16(53.3)$ & $0(0)$ & $16(26.7)$ \\
\hline Term & $09(30.0)$ & $30(100.0)$ & $39(65.0)$ \\
\hline Late term & $04(13.3)$ & $0(0)$ & $04(06.7)$ \\
\hline Total & $30(100.0)$ & $30(100.0)$ & $60(100.0)$ \\
\hline & \multicolumn{2}{|c|}{$\mathbf{p}<\mathbf{0 . 0 1}$} & \\
\hline
\end{tabular}

Table 7: Distribution of Cases according to birth weight

\begin{tabular}{|l|c|c|c|}
\hline \multirow{2}{*}{ Birth weight } & \multicolumn{2}{|c|}{ Group } & \multirow{2}{*}{$\begin{array}{c}\text { Total } \\
\text { n (\%) }\end{array}$} \\
\cline { 2 - 4 } & $\begin{array}{c}\text { Cases } \\
\text { n (\%) }\end{array}$ & $\begin{array}{c}\text { Controls } \\
\mathbf{n}(\%)\end{array}$ & $35(58.3)$ \\
\hline Normal birth weight & $05(16.7)$ & $30(100.0)$ & $16(26.7)$ \\
\hline Low birth weight & $16(53.3)$ & $0(0)$ & $09(15.0)$ \\
\hline Very low birth weight & $09(30.0)$ & $0(0)$ & $60(100.0)$ \\
\hline Total & $30(100.0)$ & $30(100.0)$ & \\
\hline & \multicolumn{2}{|c|}{$\mathbf{p}<\mathbf{0 . 0 1}$} & \\
\hline
\end{tabular}

All the controls had birth weights above $2.5 \mathrm{~kg}$ while $25(83.3 \%)$ cases had birth weights below $2.5 \mathrm{~kg}$. Out of these 25 cases, 9 (30\%) had birth weight below $1.5 \mathrm{~kg}$ (very low birth weight).
Table 8 is a comparison of mean gestational age and mean birth weight in cases and controls.

Table 8: Comparison of mean gestational age and mean birth weight in cases and controls

\begin{tabular}{|l|l|c|c|c|c|}
\hline \multicolumn{1}{|c|}{ Variable } & \multicolumn{1}{|c|}{ Group } & Number & Mean & SD & p \\
\hline \multirow{2}{*}{ Gestational age (weeks) } & Cases & 30 & 36.54 & 3.98 & $<0.05$ \\
\cline { 2 - 5 } & Controls & 30 & 39.77 & 2.01 & \\
\hline \multirow{2}{*}{ Birth weight $(\mathrm{kg})$} & Cases & 30 & 2.19 & 0.54 & $<0.05$ \\
\cline { 2 - 5 } & Controls & 30 & 2.87 & 0.48 & \\
\hline
\end{tabular}

Mean gestational age and mean birth weight were significantly less in cases as compared to controls $(\mathrm{p}<0.05)$.

Table 9 shows the distribution of cases according to neonatal reflexes. On follow up, a total of 11 cases $(36.7 \%)$ had deranged reflexes.
Table 10 shows the distribution of cases according to neurological assessment.

Table 11 shows the distribution of cases according to incidence of neurodevelopmental delay. On neurological assessment by Amiel Tison scale, a total of $20(66.7 \%)$ cases were observed to have deranged neurological development.

Table 9: Distribution of cases according to neonatal reflexes

\begin{tabular}{|l|c|c|c|}
\hline \multirow{2}{*}{ Neonatal reflexes } & \multicolumn{2}{|c|}{ Group } & \multirow{2}{*}{$\begin{array}{c}\text { Total } \\
\text { n (\%) }\end{array}$} \\
\cline { 2 - 4 } & $\begin{array}{c}\text { Cases } \\
\text { n (\%) }\end{array}$ & $\begin{array}{c}\text { Controls } \\
\mathbf{n}(\mathbf{\%})\end{array}$ & $49(81.7)$ \\
\hline Normal & $19(63.3)$ & $30(100.0)$ & $11(18.3)$ \\
\hline Deranged & $11(36.7)$ & $0(0)$ & $60(100.0)$ \\
\hline Total & $30(100.0)$ & $30(100.0)$ & \\
\hline
\end{tabular}

Table 10: Distribution of cases according to neurological assessment

\begin{tabular}{|l|c|c|c|}
\hline \multirow{2}{*}{ Amiel Tison neurological assessment } & \multicolumn{2}{|c|}{ Group } & \multirow{2}{*}{$\begin{array}{c}\text { Total } \\
\text { n (\%) }\end{array}$} \\
\cline { 2 - 4 } & $\begin{array}{c}\text { Cases } \\
\mathbf{n}(\%)\end{array}$ & $\begin{array}{c}\text { Controls } \\
\mathbf{n}(\%)\end{array}$ & $40(66.7)$ \\
\hline Normal & $10(33.3)$ & $30(100.0)$ & $20(66.7)$ \\
\hline Deranged & $20(66.7)$ & $0(0)$ & $60(100.0)$ \\
\hline Total & $30(100.0)$ & $30(100.0)$ & \\
\hline \multicolumn{3}{|c|}{$\mathbf{p}<\mathbf{0 . 0 1}$} \\
\hline
\end{tabular}


Table 11: Distribution of Cases according to incidence of neurodevelopmental delay

\begin{tabular}{|l|c|c|c|}
\hline \multirow{2}{*}{$\begin{array}{c}\text { Developmental delay } \\
\text { Trivandrum developmental } \\
\text { scoring system) }\end{array}$} & $\begin{array}{c}\text { Cases } \\
\text { n (\%) }\end{array}$ & $\begin{array}{c}\text { Controls } \\
\mathbf{n}(\%)\end{array}$ & \multirow{2}{*}{$\begin{array}{c}\text { Total } \\
\mathbf{n}(\%)\end{array}$} \\
\cline { 2 - 4 } & $11(36.7)$ & $0(0)$ & $11(18.3)$ \\
\hline Yes & $19(63.3)$ & $30(100.0)$ & $49(81.7)$ \\
\hline Total & $30(100.0)$ & $30(100.0)$ & $60(100.0)$ \\
\hline
\end{tabular}

Developmental delay was assessed by the Trivandrum Developmental Scoring System. At 6 months of age, a total of $11(36.7 \%)$ cases with risk factors had developmental delay.

Only one $(3.3 \%)$ case had abnormal ophthalmic examination findings. None of the cases had abnormal auditory examination findings.

\section{Discussion}

The present study compared the patterns of development and neurological status of normal infants and high-risk infants. In the present study, overall there were $55 \%$ females and $45 \%$ males with no significant difference between cases and controls $(\mathrm{p}=1.0)$. All controls were term babies while 53.3\% cases were pre-term and $13.3 \%$ cases were postterm. Out of the total 30 cases with risk factors, 25 were low birth weight. Mean gestational age and mean birth weight were significantly less in cases as compared to controls $(\mathrm{p}<0.05)$. On follow up, a total of $6.7 \%$ cases had a head circumference below $3 \mathrm{rd}$ percentile and $13.4 \%$ cases had length below the 5 th percentile.

Developmental delay was observed in a total of $36.7 \%$ of the cases with risk factors. Neurological assessment by Amiel Tison scale showed that a total of $66.7 \%$ cases have deranged neurological development while $3.3 \%$ cases had abnormal ophthalmic examination findings. Calame A, et $a l^{11}$ in their study observed a $29 \%$ incidence of developmental delay in high-risk infants and Shrestha M, et $a l^{12}$ in their study observed that $29 \%$ high-risk babies, had global delay which is less in comparison to our study. However, Resegue $\mathrm{R}$, et $a l^{13}$ in their study on high-risk infants observed developmental delay in $52.6 \%$ cases which is more in comparison to our study. A higher incidence of neurodevelopmental delay in comparison to the present study was also observed in the studies by Sass AH, et al $(79.3 \%)^{14}$ and Sudhir U, et al $(65.2 \%)^{15}$. Chatterjee et $a l^{16}$ in their study on outcome of high-risk newborns discharged from special care baby units observed neurodevelopmental delay in $31.6 \%$ cases which is similar to our study

Chaudhari S, et $a l^{17}$ studied the mortality and morbidity in high-risk infants after hospital discharge. Mortality was significantly higher in the very low birth weight group and $72.7 \%$ of the hospital deaths were due to infection. In contrast to this, the present study observed no mortality.

Sudhir $\mathrm{U}$, et $a l^{15}$ studied the outcome of growth and development till one year of age of very preterm neonates and moderate to late preterm neonates admitted and discharged from a tertiary level NICU in Central India. Overall growth (all anthropometric parameters) was higher in the moderate to late preterm group. In very preterm babies weight gain was better from 6-12 months of postnatal age and was statistically significant $(p<0.05)$. Length gain was higher in very premature babies' group but not statistically significant and head growth was significantly higher in very preterm babies from 1 month to 1 year compared to moderate to late preterm babies $(p<0.05)$. They concluded that prematurity and its associated complications are linked to adverse physical and neurodevelopmental outcomes. Improved perinatal care, early assessment of development by appropriate tools and early intervention is a must to improve the outcome of these babies and similar observations are seen in this study.

\section{Conclusions}

In this study the incidence of developmental and neuro-developmental delay in high-risk neonates was significantly high with low birth weight and prematurity being the main contributors.

\section{References}

1. Carlo WA. The high-risk infant. Nelson textbook of pediatrics. 19th ed. Philadelphia, PA: Saunders. 2011; 552. https://doi.org/10.1016/B978-1-43770755-7.00091-9

2. Ho LY. Follow-up care and outcome evaluation of high-risk preterm infants: A life-course commitment. Annals of the Academy of Medicine, Singapore 2018; 47(2): 551-6.

3. Escobar G, Littenberg B, Petitti DB Outcome among surviving very low birth weight infants: a meta-analysis. Archives of Disease in Childhood 1991; 66: 204-11. 
https://doi.org/10.1136/adc.66.2.204

PMid: 1825773 PMCid: PMC1792838

4. Saigal S, Doyle LW. An overview of mortality and sequelae of preterm birth from infancy to adulthood. The Lancet 2008; 371(9608):261-9.

https://doi.org/10.1016/S01406736(08)601 36-1

5. Chaudhari S, Kulkarni S, Barve S, Pandit AN, Sonak U, Sarpotdar N. Neurologic sequelae in high risk infants--a three year follow up. Indian Pediatrics 1996; 33(8):645-53.

6. Paul VK, Radhika S, Deorari AK, Singh M. Neurodevelopmental outcome of 'at risk' nursery graduates. Indian Journal of Pediatrics 1998; 65(6): 857-62.

https://doi.org/10.1007/BF02831347

PMid: 10773950

7. Sukumaran TU, Vijesh PV, Sukumaran PS. Developmental delay and disabilities in high risk newborns- a follow up study. Journal of Rehabilitation Council of India 2008; 4(1\&2):18-24.

8. Baburaj S, Abraham B, Vasant PV, Raj S, et al. Growth and development till one year from a rural neonatal intensive care unit in south India. International Journal of Biomedical Research 2013; 4(12):695-700. https://doi.org/10.7439/ijbr.v4i12.445

9. Luo YF, Zheng K, Zhou XJ, Liang JF. Mental development of high-risk neonates: a long-term follow-up study. World Journal of Pediatrics 2006; 15(2):121-4.

10. Molteno CD, Thompson MC, Buccimazza SS, Magasiner V, Hann FM. Evaluation of the infant at risk for neurodevelopmental disability. South African Medical Journal 1999; 89(10):1084-7.

11. Calame A, Reymond-Goni I, Maherzi M, Roulet M, Marchand C, Prod'hom LS, et al. Psychological and neurodevelopmental outcome of high risk newborn infants Helv Paediatr Acta 1976; 31(4-5):287-97.
12. Shrestha M, Bajracharya L, Shrestha L. Neurodevelopmental outcome of high risk babies at one year of age born in a tertiary centre. Journal of the Nepal Paediatric Society 2017; 37(1):45- 50. https://doi.org/10.3126/jnps.v37i1.16242

13. Resegue R, Puccini RF, da Silva EMK. Risk factors associated with developmental abnormalities among high-risk children attended at a multidisciplinary clinic. Sao Paulo Medical Journal 2008; 126(1): 410.

https://doi.org/10.1590/S15163180200800 0100002

PMid: 18425280

14. Sassá AH, Higarashi IH, Bercini LO, Arruda DC, Marcon SS. At-risk infants: monitoring children's growth in the first year of life. Acta Paulista de Enfermagem 2011; 24(4):541-9.

https://doi.org/10.1590/S01032100201100 0400015

15. Sudhir U, Ghanghoriya P, Barman M, Joshi T. Growth and neurodevelopmental outcome of high risk premature neonates at 1 year in a tertiary level NICU of central India. International Journal of Contemporary Pediatrics 2017; 4:1787-91. https://doi.org/10.18203/23493291.ijcp20 173786

16. Chatterjee, Nandita \& Mitra, Kaninika. Neurodevelopmental outcome of high risk newborns discharged from Special Care Baby Units in a rural District in India. Journal of Public Health Research 2015; 4: 318.

https://doi.org/10.4081/jphr.2015.318

PMid: 25918689 PMCid: PMC4407034

17. Chaudhari S, Kulkarni S, Pandit A, Deshmukh S. Mortality and morbidity in high risk infants during a six year followup. Indian Pediatrics 2000; 37(12):131420. 